\title{
Blending issues and stakeholders: in pursuit of the elusive synergy
}

\author{
John F. Mahon ${ }^{1}$ | Pursey P.M.A.R. Heugens ${ }^{2}$ | Richard A. McGowan ${ }^{3}$
}

\author{
${ }^{1}$ Maine Business School, University of Maine, \\ Orono, Maine, USA \\ ${ }^{2}$ RSM Erasmus University, Rotterdam, The \\ Netherlands \\ ${ }^{3}$ Wallace E. Carroll School of Management, \\ Boston College, Chestnut Hill, Massachusetts, \\ USA

\section{Correspondence} \\ John F. Mahon, Maine Business School, \\ University of Maine, Orono, ME 04469-5703. \\ Email: mahon@maine.edu
}

\begin{abstract}
Two separate frameworks have existed for the analysis of social predicaments in which businesses play a role: issues management and stakeholder management. In this paper, we argue that the chasm dividing these two literatures is artificial, and potentially obstructive to the advancement of our knowledge of the position of business in contemporary societies. The position we take in the present paper is that all social predicaments have an issues side as well as a stakeholder side and that a dual focus on both issues and stakeholders is therefore essential to understanding the evolution of these predicaments and crucial to managerial dealings with these issues. We present an integrative co-evolutionary framework, explaining the dynamics between issues and stakeholders in all consecutive stages of a predicament's evolution. The framework proposes a new way of thinking about issues and stakeholders, as such facilitates a deeper understanding of how the social environment of business is constituted, and offers new insights for the practical management of issues and stakeholders.
\end{abstract}

\section{1 | INTRODUCTION}

When key organizational decision-makers have to navigate their firms through the challenging and often uncharted waters of the social and political environments in which they operate, they face two theoretical options, with very different practical implications. The first is to identify all key organizations and groups that are influenced, directly and indirectly, by the organization's decisions that may affect organizational outcomes. Sensible managers will recognize that these stakeholders are sometimes parties with whom the organization already has a well-developed, on-going relationship, whereas at other times, they are parties that only have relationships with other influential actors in the organizational network, but whom can exert indirect influence on the organization through these relationships, and in some situations, there are no preexisting relationships of any kind. Once these stakeholders are identified, managers can prioritize them according to their power over the corporation and the urgency and legitimacy of their claims (Mitchell, Agle, \& Wood, 1997). Realizing that organizational resources and attention are always scarce, managers can then use the outcome of this prioritization exercise to accommodate the needs of the most powerful and/or urgent of these stakeholders, provided the organization has carefully identified all the key stakeholders. Note carefully the use of the term "key stakeholders"searching out all of the actual and potential stakeholders, directly and indirectly impacted, is we believe a futile exercise.
The second option open to key decision-makers is to focus not so much on these groups per se, but rather on the social predicaments facing the organization. Regardless of whether these social predicaments are called strategic, public, or social issues, they all have the potential to interfere with the organization's attempts to realize its strategic intent if they are left unattended. In the traditional issues management process, decision-makers first scan the organizational environment for new predicaments emerging on the horizon. Next, they monitor these issues throughout their life cycle, in order to interpret their nature and to evaluate their potential consequences. Finally, they come up with an appropriate set of responses, timed to the life cycle of the issue and to the ability of the organization to influence the issue.

Managers will of course realize that separating these two options is not a practical choice in real life. If they focus on their current set of stakeholders only, there is a fair chance that they will miss out on new threats and opportunities emanating in their environments. If they focus on issues only, they may suffer reputational damage, as they get known as reactive fire fighters rather than pro-active fire preventers. Yet in the business and society and strategic management literature, Chinese walls seem to separate the bodies of work on issues management and stakeholder theory and practice, to which these options correspond. In the present paper, we argue that this situation is conceptually and practically undesirable, as both perspectives can at best offer only a partial and incomplete understanding of social predicaments. 
We view such social predicaments as controversies (economic, political, social, or any combination) that may have a negative effect on the ability of organizations to realize their strategic intent if left unattended (others refer to these types of situations as "wicked problems"; see Head \& Alford, 2015; McMillan \& Overall, 2016). Social predicaments always have an issue side (in that they involve a disagreement over the distribution of resources and positions) as well as a stakeholder side (in that they affect or address a number of actors, who will then automatically have a stake in whether and how the issue will be resolved). Social predicaments are broader than strategic issues. Strategic issues must of necessity be identified with something-generally an organization in order to be "strategic." Social predicaments exist independently of the organization and have a different ontological status. ${ }^{1}$ We will present a co-evolutionary framework in this paper, pointing out how stakeholders influence issues and vice versa, throughout the various interlinked evolutionary stages of a societal predicament. On the one hand, stakeholders help to frame issues and use symbols to raise the visibility of a particular set of issues in order to build awareness and coalitions and achieve their desired solution or preferred outcome(s) (Chong, 1996; Cobb \& Elder, 1983; Edelman, 1968; Mahon, 1989; Mitnick, 2001; Rochefort \& Cobb, 1994; Schattschneider, 1960). Alternatively, issues affect a number of parties in any of the arenas in which the issue is played out, and as such, they "hand-pick" certain parties that will become stakeholders, predestinating them into activism because they hurt them in their interests. Before presenting our framework, we first briefly review the two perspectives on social predicaments separately. The context of the analysis that follows is focused on newly emerging issues. Issues that currently exist generally have well-known dimensions, and the stakeholders and positions are equally clearly drawn.

\section{I TWO PERSPECTIVES ON SOCIAL PREDICAMENTS}

The discussion as to whether social predicaments can best be understood from an issues perspective or from a stakeholder perspective is highly similar to the long-standing debate in physics on the nature of light. $^{2}$ In 1690, Christian Huygens proposed a theory that explained light as a wave phenomenon. In 1704, Sir Isaac Newton offered a competing explanation, stating that light was composed of little particles emitted by luminous bodies. Both theories explain certain essential aspects of the nature of light equally well (such as reflection and refraction), whereas there are other phenomena, which can only be explained from a wave view (interference, diffraction, and polarization). The photoelectric effect (which was discovered by Hertz in 1887), however, can only be understood from a particle perspective. This analogy is telling, because issues management and stakeholder theories can be used to explain certain aspects of social predicaments equally well. There are certain aspects of societal problems that require an issues perspective, however, whereas other aspects need a

${ }^{1}$ In some ways, social predicaments may be analogous to campaigns in the social movement literature. They do have the potential to mature into a social movement if not dealt with in a timely and proper manner.

${ }^{2}$ The authors thank our colleague Bryan Husted for suggesting this analogy. stakeholder explanation. Ergo: If we want to understand social predicaments in their entirety, we need a framework that can accommodate issues and stakeholder considerations simultaneously. Or to put it in another way, we need to deal with the what (issue) and the who (stakeholders) simultaneously and continuously as the issue unfolds (with competing issue definitions) and as stakeholders enter and exit the situation over time. This is the problem facing managers in dealing with such situations-the issue (the substantive content) and the players involved (stakeholders) need to be addressed simultaneously. We will present an integrative framework below, but first, we discuss both sides of the social predicaments coin (i.e., issues and stakeholders) separately.

\section{1 | Issues}

What is an issue (for a more in-depth treatment of issues management, see Mahon, 2017)? An issue can be a disagreement over facts, values, and/or policies (Waddock \& Mahon, 1991) or a disagreement over procedural or substantive matters related to the distribution of resources or positions (Cobb and Elder, 1983). An issue can also be a controversial inconsistency based on one or more expectational gaps involving management perceptions of changing cost/benefit positions that occur within or between views of what is and/or ought to be corporate performance or stakeholder perception of corporate performance that implies an actual/anticipated resolution that creates significant, identifiable present, or future impacts on the organization (Wartick \& Mahon, 1994). The essential trichotomy of elements in an issue, (a) what is versus what is (factual disagreements), (b) what is versus what ought to be (a clash of facts and values), and (c) what ought to be versus what ought to be (a clear clash of values), is crucial. Just exactly what is the basis of the disagreement or inconsistency, and what position (fact, value, or policy) is crucial for a variety of reasons.

One impact of this trichotomy is that it is useful in identifying the basis for initial stakeholder involvement, and such identification allows for assessments of the arguments, approaches, and likely initial positioning of stakeholders on the issue. That is, some stakeholders will become involved for ideological reasons (perhaps based on value positions or on previous history with the issue and others involved in its resolution), while others will become engaged because of fact-based concerns, yet others may become involved because of concerns with the process of resolution. Clearly, the driving reason for involvement being held by each stakeholder is important to both the formulation of strategy and tactics and the formation of alliances on an issue. In addition, this incentive for involvement may be helpful in assessing the power, urgency, and legitimacy of a given stakeholder. In other words, how issues evolve is primarily a function of three factors, notably: (a) which stakeholders become involved in an issue (differences in influence-which reflect the basis of their initial involvement; ideology vs. fact-based concerns), (b) the timing of their involvement (receding zone of discretion), and (c) the outcome that they prefer (preferences shape actions and hence the evolution of the issue). Figure 1 is a broad new look at how issues evolve.

Our basic presumption is that all issues start in some primordial state. While in this state, chance reigns supreme, and utter confusion is the order of things. What this means to suggest is that there are 


\section{Broad types of issues}

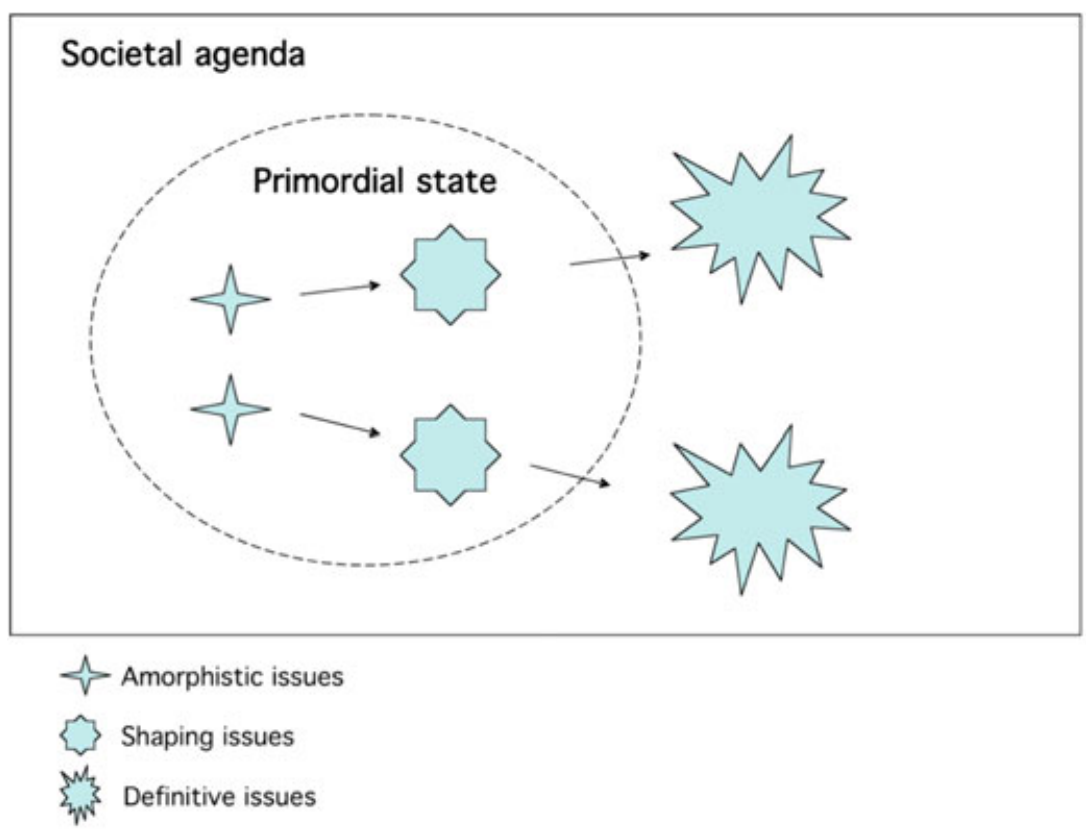

FIGURE 1 Broad type of issues

literally millions of potential issues out there for action and consideration by organizations and stakeholders. Hence, the process by which "issues" emerge is critically important (and may in fact differ substantially by geographic location, culture mores, political systems, and the like), because many issues never make it past their infancy stage. This is particularly challenging as we consider how social media and the Internet has changed the velocity of issue emergence globally. We offer the following definitions for your consideration:

- Amorphistic issues: an issue without definite character or nature, lacking in organization and unity, and having no real or apparent form, literally the absolute "raw" state of issues. It may exist simply as awareness that "something" is not right, but it has no specificity; for example, the public transit service is just not "right."

- Shaped (or shaping) issues: an issue with visible makeup characteristics of a particular item or kind of item; the condition in which someone or something exists at a particular time (both real and substantively and/or perceived and symbolically). The issue is assuming shape; potentially, many stakeholders are defining it, and responsibility for action is diffused as is the appropriate arena for resolution. An example was the set of problems facing Hewlett Packard over the alleged illegal investigations of leaks of confidential information from the Board of Directors that was approved by the CEO. The issue is assuming a shape-but is it an issue of illegal activity? Of a CEO overstepping the bounds of proper behavior? Of an external investigator going too far? Of poor and improper communications? Of vagueness in the law itself? Of poor corporate governance?

- Definitive issues: An issue, which has "escaped the swamp," has achieved visibility and definition to more than one stakeholder and has clear (but can be broad) identity and for which it is possible for individual stakeholders or groups of stakeholders to build momentum on. As we will note below, definitive issues can regress if issue momentum is lost; for example, disinterest over time with the issue, the issue is replaced by more pressing issues, or no single (or narrow set) of definitions gain traction, or the issue goes through a process of splintering. Genetically modified organisms are one such issue-it is defined by those in Europe and elsewhere as a public health and safety issue. In the United States, it is being defined as a trade issue, and both issue definitions are being played out across the world with different stakeholder involvements and likely different organizational impacts.

By issue definition, we mean a statement of the meaning of a word, word group, or a sign or symbol. The action or the power of describing, explaining, or making definite and clear sharp demarcation of outlines or limits is part of this defining process. Definitive issues have threshold levels of clarity (either real, symbolic, or both) that are significant enough to allow for stakeholder involvement and engagement in debate/discussion in larger public forums and for the formation of coalitions and alliances among and across stakeholders. Definitive issues tend to be time bound (of limited existence or capable of maintaining broad public interest for limited periods) and seek an arena for resolution. It is between amorphistic and shaped issues that an organization or stakeholder can impact the emergence of an issue (for example, driving an issue to a particular arena for resolution, driving an issue to be merged with another existing issue, or supplanting that existing issue). It is between shaped and definitive issues that the process of issue engagement (encounters with stakeholders) truly unfolds. Any given issue can bounce back and forth between amorphism and shaping in the pre and emergent stage and bounce back and forth between shaping and definitive issues. The "bouncing" is often driven by specific strategies and tactics of organizations and stakeholders, or by events external to the specific issue at hand.

Figure 2 (to be introduced later in this analysis) is a follow-up to Figure 1-it presumes that an issue has emerged from the swamp 


\section{An integrative framework}

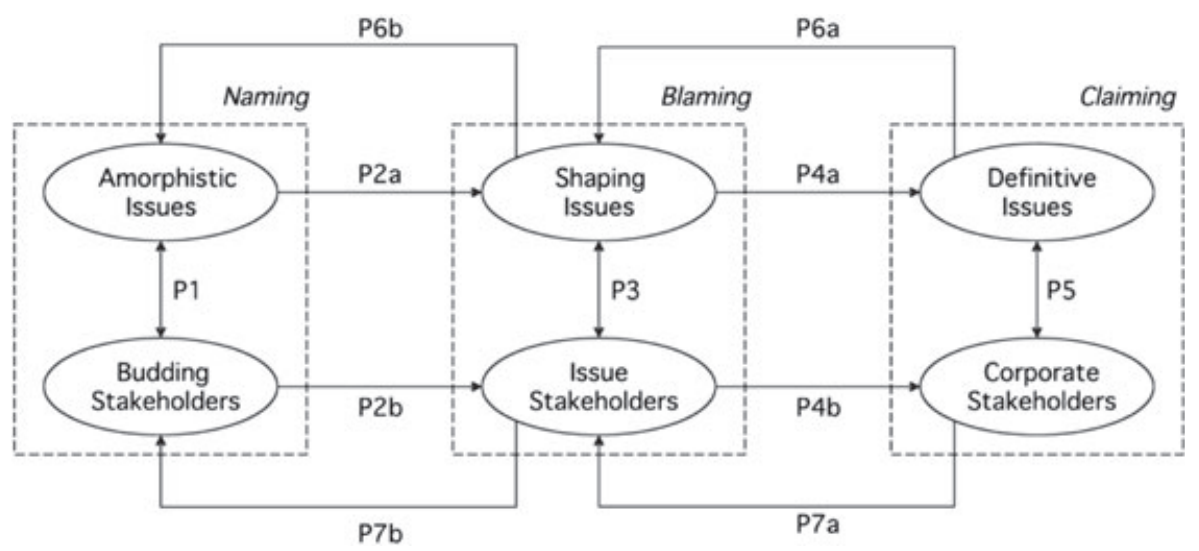

FIGURE 2 An integrative framework

described earlier and is not subjected to stakeholder and organizational action in the "swamp"; that is, actions are visible to others and can engender reactions. It is important here to recall the observations of Schattschneider (1960). He noted that in any public contest, the "winner" is determined by whose side the audience supports (Cobb \& Elder, 1983; Mahon, 1989; Rochefort \& Cobb, 1994). It is the attraction (and in some cases the perceived attraction is enough to compel action) of the general public-or key stakeholders to one's position that leads to success-but this attraction and building of momentum can only be undertaken if two conditions are met. First, the issue has to be what we have termed definitive. How can we determine stakeholder interest (much less position and strategy) without a clear issue, or at a minimum a small number of competing definitions? Second, the issue has to be "visible" to more than one stakeholder (otherwise how can stakeholders get involved?). This naturally raises the question of where (strategically/tactically/positionally) and when a stakeholder should engage in the issue. In order to better understand this, we need to have a deeper understanding of what stakeholders are and how they become involved in an issue.

\section{2 | Stakeholders}

What is a stakeholder? The Stanford Research Institute is usually credited for coining the actual term in 1963, but it has been Freeman who has popularized the phrase with his oft-cited 1984 book Strategic Management: A Stakeholder Approach. The main title of this important book-Strategic Management-is interesting for at least two reasons. First, the book clearly formulates an instrumental (in contrast to normative) stakeholder theory. Freeman emphasizes that organizations should develop stakeholder management capabilities in order to ensure that they can obtain their most preferred outcomes in the societal arena. In this view, the sole criterion for granting a party stakeholder status is prudence, not some deeper underlying ethical principle. With this modern history of stakeholder management in mind, it remains a remarkable fact that stakeholder theory has been embraced (some would say hijacked) by business ethics scholars after 1984 to such an extent that it has almost become heresy to point out that companies can and must adopt stakeholder strategies for instrumental reasons. With respect to the question of stakeholder definition, a second implication of the title of Freeman's (1984) work is more important. The discipline of strategic management is exclusively focused on key decision-makers in organizations and aims at explaining how they can make their organizations rise above competitive parity (Rumelt, Schendel, \& Teece, 1991). Hence, a book that looks at stakeholder issues through a strategic management lens is guaranteed to focus exclusively on corporate stakeholders. We do not argue that corporate stakeholders are not an important category of stakeholders, but it would certainly be imprudent to stop our analysis here. If we adopt a public affairs or issues management perspective, it becomes clear that not only corporations but also issues too can have stakeholders. Parties can feel that they are or are going to be affected by a specific issue, even if they are still in limbo with respect to who is to blame for the situation. Hence, in addition to recognizing corporate stakeholders, it is also important to note that there are issue stakeholders, who define their identity as a stakeholder more in respect to the issues facing them than to the companies or other actors involved with those issues. ${ }^{3}$ These issue stakeholders profile their identities around certain issues that either affect them or that they have chosen to focus on. For example, the "Greens" tend to focus their efforts and become involved in those issues that deal with the environment, and animal rights groups (e.g., People for the Ethical Treatment of Animals) tend to focus on issues of import to animals. It does not matter to them "who" the foe is-corporation, government, and the general public-it is the issue that drives actions. Nonetheless, such issue-oriented stakeholders can engage in contests with corporations -as corporations can become the focal player around which the issue itself revolves. Often, corporations underestimate the ideological fever and passion with which these issue-oriented stakeholders act or fail to consider them at all. Issue-based stakeholders have great capacity to surprise other players in an issues contest.

More importantly even, we believe that stakeholders can switch between being a corporate stakeholder and an issue stakeholder, and

\footnotetext{
${ }^{3}$ Indeed, we would argue for the existence of "process" stakeholders that are different in orientation and involvement than either issue or corporate-based stakeholders. These "process-based" stakeholders are concerned with fairness, access, and equitability issues around a process of resolution. They are not interested in any specific outcome per se, but in the fairness of the process that is used to deal with and resolve the issue.
} 
back again. What is more, we believe that prior to being a corporate or issue stakeholder, parties are often better described as budding stakeholders-parties who are only slowly beginning to realize the magnitude of certain societal predicaments and who are not yet certain about what stake it is they are holding, nor in what or whom. It is important to realize that many societal predicaments represent what Mason and Mitroff (1980) have called "wicked problems" (again see Head \& Alford, 2015; McMillan \& Overall, 2016)-problems that are too complex to be understood by any specific actor alone, that have multiple causes, and that cannot be solved in a piecemeal fashion. Yet in today's world, even though complexity is growing, so is awareness of issues and the ability to communicate across time and distance in an instant. What this means for our stakeholder is that as an issue emerges from the swamp; a stakeholder will not be able to process all the issue-relevant information that "hits" them immediately and correctly (a bounded rationality approach). As such, our "budding" stakeholders are faced with three problems: (a) those related to the complexity of the issue, (b) those related to the inherent information processing capabilities of any individual stakeholder, and (c) those related to the speed with which an issue can be advanced.

This wicked problem character has important consequences for how specific parties switch stakeholder status over time. Due to the complexity of social predicaments, stakeholders usually start out as budding stakeholders. Usually, they only realize that they are a stakeholder of something or someone because they are confronted with the symptoms of a situation that is undesirable to them or has the potential to be undesirable to them. Stakeholders may experience an unexpected degradation of their quality of life, a deterioration of their environment, or a sudden drop in the degree of satisfaction their customers express with the quality of their products and services and others. Note how the information-processing capability of the stakeholder impacts on their ability to sense an issue and when it is impacting on them. This time lag between receipt of information and sensing of relevance, pressure, and action is a critical time period for all stakeholders. At this time, budding stakeholders are struggling to make sense of the changing conditions in their environment, and the main question they seek an answer too is what is going on here? This is a dangerous time for stakeholders as other actors may enter into the contest faster than they do-and change the issue and the forum where it is being discussed and press for resolution before all stakeholders have processed what is going on. Time is not an ally in issue contests, and the advantage oft goes to those stakeholders who can move quickly and decisively.

Once a stakeholder group gets a firmer grip on what the dimensions of a specific problem are, it usually becomes a stakeholder of a specific issue. The stakeholder transforms from a budding stakeholder into an issue stakeholder. The stakeholder realizes that a social predicament is unfolding, to which there are many potential solutions, allies, competitors, and neutral parties. The stakeholder will also realize that there are certain parties in its environment with whom it shares a preference for a certain outcome, and the issue stakeholder may decide to establish coalitions with such like-minded parties in its environment in order to increase its chances of obtaining a desired solution for the predicament. Only when the stakeholder has made an inventory of which actors share its perception with respect to what desirable outcomes might be and of which actors have a different solution in mind is it in a position to transform itself into a corporate stakeholder-a party that seeks to influence the corporations (or the arena in which a solution is likely to be sought) in its environment that it perceives to stand in the way of itself reaching the most preferred solution. It can then alone or in combination with other stakeholders attempt to influence the corporation or an arena in which it has a stake-either by persuasion, cooperation, or coercion-to stop pursuing the solution that is unfavorable to the stakeholder.

Of course, the path from budding through issue to corporate stakeholder is not smooth, often crooked and full of digressions. Stakeholders may switch between issue and corporate status. One reason is that an initial choice for a specific target organization may have been incorrect. The organizations may not oppose the most desired solution of the organization after all or may not be an actor that has much say in the further evolution of the issue. Another reason is that the (environmental) conditions may have changed because the stakeholder committed himself or herself to the organization: The issue may have become defined differently, making other actors more salient in the process; the organization may have become co-opted and now share the stakeholder's most preferred solution; or the organization may have ceased to be a factor of any importance in the issue for any other reason. In addition, the potential resolution of the issue may emerge in an arena in which certain stakeholders have no standing or influence. In all of these cases, stakeholders may decide to stop being corporate stakeholders and regress to being issue stakeholders. Once they then decide who their new target is going to be, they may become corporate stakeholders again. We cannot underestimate this process of shifting back and forth from issue to corporate stakeholder, and such shifts can occur over a long period of time. This shift has enormous implications for the organization attempting to deal with stakeholders as it drives at the heart of their involvement and may explain what appears to the corporation to be an inconsistent behavior by an external stakeholder. However, it is possible for certain stakeholders to remain issue stakeholders ad infinitum. Reasons for this positioning might be explained by resource and/or focus constraints, history as a champion on certain issues, prior relationships with corporations that prevent legitimate establishment as a corporate stakeholder, and stakeholder strategies that seek to maintain the issue as an open one until such time as they see an opportunity to "win" on the issue. Similarly, some stakeholders will skip the issue stage altogether and become corporate stakeholders immediately. Reasons for this might include prior interactions with the corporation or an ideological bias toward certain industries or firms as the source of the problem. Complicating this problem, as noted earlier, is the shifting geographic origination of issues and stakeholder alignments (see Lucea \& Doh, 2012).

There are, of course, other approaches to consideration of stakeholders that have been advanced recently, but they do not consider in any detail the issues-stakeholder management challenge. Griffin (2016), for example, has looked at stakeholders from the perspective of co-creating value (see also Stout, 2012 for additional support for looking at value). Lankoski, Smith, and Van Wasserhove (2016) come at the assessment of value from the stakeholder and not the corporate perspective. In any event, the assessment of stakeholder value surrounding corporate behavior and/or issues is a difficult one to make. 
One can also look at stakeholders from an ethics perspective or a leadership perspective (see Waligo, Clarke, \& Hawkins, 2014; Weiss, 2014). Mahon and Wartick (2012) have looked at how corporations seem to profile stakeholders and alter corporate actions over time to prioritize different stakeholders, and Helmig, Spraul, and Ingenhoff (2016) have looked at how stakeholder pressure can impact implementation of corporate social responsibility programs.

\section{I TOWARD AN INTEGRATIVE FRAMEWORK OF SOCIAL PREDICAMENTS}

Previously, we introduced two remarkably similar evolutionary processes. The first described the development of amorphistic through shaping to definitive issues, whereas the second described the sequence through which stakeholders evolve from budding through issue to corporate stakeholders. There is a reason for this similarity, and the reason is that both represent different sides of what in larger terms we have called a social predicament. Social predicaments always have an issue "or what" side (two or more different perspectives on what a desired outcome for the predicament would be) and an actor "or who" side (the initiators of the predicament and the affected parties). Obviously, social predicaments are not stable over time, but they change in terms of form and substance. We will describe three phases in the evolution of a social predicament: naming, blaming, and claiming. Because all three of these phases have an issue as well as an actor side, it is best to look at the evolution of social predicaments as a co-evolutionary process, in which stakeholders influence the progression of issues through their life cycle and vice versa.

According to Lewin and Volberda (1999: 527-528), co-evolutionary frameworks have the following properties: (a) They are longitudinal (in the sense that they study social systems over time); (b) they are contextual (they look at how phenomena or actors are embedded in their larger social context); (c) they consider multidirectional causalities (with actors or systems exerting reciprocal influences on one another, rather than just unidirectional influences); (d) they incorporate mutual, simultaneous, lagged, and nested effects; (e) they allow for path dependence; (f) they incorporate changes occurring at the level of different institutional systems; and (g) they accommodate economic, social, and political macro variables.

Even though this list of criteria is rather restrictive (and we think meeting all of the criteria in actual practice is unlikely), we believe that the framework we propose may appropriately be called co-evolutionary because it is at least longitudinal in the sense that it tracks the evolution of social predicaments over time. It is contextual in that it looks at stakeholders as actors that are embedded in multiple (political, social, and economical) arenas simultaneously, rather than that it focuses on their relationship with a focal firm alone. It allows for multi-directional causality in that it acknowledges that stakeholders shape issues, whereas issues determine which stakeholders are involved and suggest, following Preston and Post (1975), that the interactions themselves shape the issue, the stakeholder, and the very processes of interaction (what they have termed "interpenetrating systems"). It incorporates lagged effects because it incorporates feedback loops, allowing stakeholders and issues to regress to previous stages in their evolution. Finally, it is also path dependent in that it predicts an evolutionary trajectory or developmental process for both issues and stakeholders, incorporating multiple stages, which cannot be skipped or passed at will. Figure 2 introduces a co-evolutionary framework, which integrates the issue and stakeholder perspectives.

\section{1 | Phase 1: naming}

${ }^{4}$ Naming allows for positions to be formed around an issue, for stakeholders to get involved (and assess saliency, urgency, and power), for coalitions and alliances of interested parties to form, and for an agenda to be developed and an arena for the resolution of the issue. Consider the Enron debacle-is it an issue of corporate greed/misconduct, a failure of the SEC to provide proper regulatory oversight, a failure of one accounting firm, or a failure of the entire accounting profession? It should be clear that the naming of an issue provides a great deal of insight into which stakeholders are likely to become engaged, whether the issue is to be centered on facts/values/policy, and in which arena the issue is likely to be resolved. In some cases, a public issues champions, like Ralph Nader, Rachael Carson, Dr. Martin Luther King, Rev. Jesse Jackson, or the Greens, can lead in naming an issue or problem. Once the issue or problem is named, blaming can occur. This suggests the following propositions:

Proposition 1. In the naming phase of a societal predicament, amorphistic issues begin to take shape when it becomes clear which parties it affects; previously disinterested parties transform into budding stakeholders when they are confronted with the symptoms of an emerging amorphistic issue.

Proposition 2a. Amorphistic issues evolve into shaping issues when cause-effect relationships are becoming more evident (due to new facts becoming available and stakeholder information processing), which makes it possible to start addressing the parties that played a role in the initiation of the issue. Issue champions and external events can have impact hereespecially on the speed with which an issue moves to resolution.

Proposition $2 \mathrm{~b}$. Budding stakeholder transforms into issue stakeholders once an issue has gained some initial shape and boundaries. An issue stakeholder is a party that realizes that it is affected by an issue and that is now "mapping the terrain"-looking for supporters (with whom it shares an outcome preference) and culprits (whom have a preference for a different outcome). In this stage, stakeholders are in a search for allies to share the costs, efforts, and risks in dealing with the issue and to assess the likelihood of "winning" on this issue at this time, with this constellation of stakeholders, and in the likely arena of resolution.

\section{2 | Phase 2: blaming}

Blaming involves the identification of a culprit (individual, organization, process, government, and others) to hold responsible for the problem/issue. The critical component of blaming is not that it assigns

${ }^{4}$ Felstiner, Abel, and Sarat (1980-1981) first suggested the distinction between and among naming, blaming, and claiming. 
responsibility but that it suggests a plan for the resolution of a problem, potential alliances to deal with the resolution of the issue, and a specific arena for resolution (legislative, regulatory, judicial, and others -see Mahon \& McGowan, 1996 for a more in-depth discussion of the arena concept) and points, in a general way to a culprit or set of culprits. We have been witnesses to the spectacle of Ford and Firestone battling over who was to blame for the car accidents that occurred using both of their products. This was not a simple exercise in rhetoric. Both firms knew that the assignment of blame would bring significant pressure on the firm and assigned the blame with the associated impact on image and costs. If, on the other hand, blame could be assigned to the National Highway Traffic Safety Agency for regulatory failures, both firms might be able to escape with little damage (either to image or to costs). The national hearings in the United States on the September 11 tragedy are a clear exercise in blaming-determining "who" or what agency of government contributed to the unfolding sequence of events. After blaming is settled, claiming can occur.

Proposition 3. In the blaming phase of a societal predicament, an issue takes on a more narrowly focused initial shape; this shape may be seen as an initial proposal for redistribution of resources and positions, thereby affecting the stakeholders involved (as some of them will stand to gain and others to lose). These stakeholders in turn affect the shape of the issue, as they look for supporters and culprits to change the initial solution or shape in their favor. In addition, stakeholders search for playing fields (or arenas) in which the issue might ultimately be resolved/addressed.

Proposition 4a. A shaping issue transforms into a definitive issue when a definition (or multiple definitions) has been reached to which a group (or groups) of stakeholders agree. This definition involves a more or less definitive choice for an arena in which the issue will be resolved, an identification of the issue's culprits, and one or several avenues for solution. The focus now is on competing definitions of the issue, and the battle is between stakeholder networks and alliances for issue definition supremacy, or for arena resolution specification.

Proposition 4b. An issue stakeholder transforms into a corporate stakeholder once a stakeholder decides (a) which party to target (the main obstacle standing in the way of the stakeholder's most preferred solution) and (b) what changes to demand from that party.

\section{3 | Phase 3: claiming}

Claiming is where specific demands are made upon someone (usually the blamed organization) to deal with the problem or issue. For example, in order to obtain funding for AIDS, supporters had to overcome two hurdles. They had to convince all interested stakeholders that the disease was brand new and that existing treatment modalities would not work. Next, they had to convince all stakeholders that significant new funds for research and treatment would be required (see Cobb and Ross, 1997, Chapter 2). Not that claiming is not a guarantee that funds will be provided or that the issue will actually be resolved.
Proposition 5. In the claiming phase of a societal predicament, an issue has taken on a definitive shape, which-almost dramaturgically-assigns stakeholders their specific roles; the corporate stakeholders that are involved with the issue now know exactly which parties to address and what to ask for, in the context of a specific arena for resolution.

\subsection{Regress to previous stages}

Any given issue can bounce back and forth between amorphism and shaping in the pre and emergent stage and bounce back and forth between shaping and fully formed. The "bouncing" is often driven by specific strategies and tactics of organizations and stakeholders, or by events external to the specific predicament at hand. Similarly, any given stakeholder can bounce back and forth between the budding stakeholder stage and the issues stakeholder stage and bounce back and forth between the issue stage and the corporate stage. This "bouncing" is often driven by specific changes in the definition of the issue, by clever strategies and tactics that play significant stakeholders (or stakeholder groups) off against one another, by successful blurring and fragmentation of the issue, or by events external to the specific predicament at hand.

Proposition 6a. Definitive issues can regress toward shaping issues as stakeholders question or as new facts challenge the present definition of the issue (note: here, there is something wrong with the proposed solution).

Proposition 6b. Shaping issues can regress toward amorphistic issues as the initial solution as once established cause-effect relationships are proven wrong (note: here, there is something wrong with the problem definition). For example, before Nader started addressing the safety of cars as "the issue," automotive manufacturers in the United Sates were attempting to frame the issue as one of "driver qualifications."

Proposition 7a. Corporate stakeholders can regress toward issue stakeholders once. They realize that the corporation they targeted is not the most appropriate culprit (note: here, something went wrong with respect to targeting the most appropriate culprit).

Proposition 7b. Issue stakeholders can regress toward budding stakeholders once their beliefs concerning the impact or shape of a social predicament are disproved (note: here, there is something wrong with perceiving or interpreting of the symptoms of a societal predicament). ${ }^{5}$

\section{4 | CONCLUSION}

The development of issues and problems is a complicated process. Leaping to stakeholder management concerns and tactics without clarity on the issue seems to us to be fraught with problems. At every turn in the development of an issue, actors with stakes and interests can come and go, and every stakeholder can take a shot at naming the

\footnotetext{
${ }^{5}$ Note that for ideologically drive stakeholders, they will not admit defeat, will not withdraw, and will not regress. Their commitment to the cause is all consuming-and as such, this is a special case.
} 
problem. Even those issues, which we have called definitive, can be obscured, narrowed, widened, or eliminated from visibility and public interest by a clever stakeholder action.

Recognizing that issues do go through is clear, and at times, discrete stages are the first step in developing responsible and effective stakeholder response and management strategies. What becomes confusing is that the process is not necessarily linear-and may be circular. A stakeholder may believe an issue has been "handled" when it has regressed to a previous stage and can emerge again in another guise with different configurations of stakeholder involvement. An awareness of the stages of issue development affords all stakeholders the opportunity to deal with the problem at initial stages with a limited number of other stakeholders involved and with limited public exposure and visibility. As the issue becomes more visible, so do the number of potential stakeholders involved. As the issue unfolds, the probability that it will expand and capture media attention and other stakeholders increases dramatically. This places a clear premium on the environmental scanning and sensing of the stakeholder and its ability to move quickly on an issue. It is equally important to recognize the difference between budding, issue, and corporate stakeholders and that the issue affects stakeholders and vice versa. This is often lost or obscured in analyses of stakeholders and issues.

Simply put, it is time to recognize that stakeholder strategies are meaningless without a simultaneous and continuous consideration of the issue(s) involved. In terms of long-range planning and positioning, issues management properly conducted can serve as a planning tool for stakeholder involvement and management and for better-focused organizational action to deal with issues as they unfold and with the portfolio of issues that all organizations deal with over time.

We have moved ahead in stakeholder management, proposing models and approaches for assessing stakeholders and their power, influence, urgency, and other characteristics-all of which is an important and a valuable research. But we have ignored the process by which stakeholders become involved because we have neglected to keep a research eye on the process by which issues unfold. No senior executive of any organization would engage in actions and tactics without a clear understanding of the strategy of the organization. We would respectfully suggest that no organization or individual should engage in stakeholder management without the following:

- understanding the nuances of issues (and stages thereto) and how these can be impacted/altered/denied/changed;

- understanding why stakeholders choose to become involved with some issues and not with others, and the basis for their involvement;

- understanding the subtle differences between issues, process, and corporation-focused stakeholders and what each needs for issue resolution;

- understanding how a "given emerging issue" interacts with existing issues and positions and strategies and stakeholders and as part of organizational history; and

- understanding how history between and among stakeholders impacts on alliances and networks with regard to both specific issues and stakeholders.
Stakeholder management and issues management are inextricably intertwined. We need more research that recognizes this fact and that can move us to deeper levels of understanding-both theoretically and practically.

\section{REFERENCES}

Chong, D. (1996). Creating common frames of reference on political issues. In D. C. Mutz, P. M. Sniderman, \& R. A. Brody (Eds.), Political persuasion and attitude change). Ann Arbor: University of Michigan Press.

Cobb, R. W., \& Elder, C. D. (1983). Participation in American politics: The dynamics of agenda building. Baltimore, MD: Johns Hopkins Press.

Cobb, R. W., \& Ross, M. H. (Eds.) (1997). Cultural strategies of agenda denial: Avoidance, attack, and redefinition. Lawrence, KS: University Press of Kansas.

Edelman, M. E. (1968). Symbolic politics. Chicago: University of Chicago Press.

Felstiner, W. L. F., Abel, R. I., \& Sarat, A. (1980). The emergence and transformation of disputes: Naming, blaming, claiming .... Law and Society Review, 15, 631-653.

Freeman, R. E. (1984). Strategic management: A stakeholder approach. Marshfield, MA: Pittman.

Griffin, J. J. (2016). Managing corporate impacts: Co-creating value. Cambridge, England: Cambridge University Press.

Head, B. W., \& Alford, J. (2015). Wicked problems implications for public policy and management. Administration \& Society, 47(6), 711-739.

Helmig, B., Spraul, K., \& Ingenhoff, D. (2016). Under positive pressure: How stakeholder pressure affects corporate social responsibility implementation. Business \& Society, 55(2), 151-187.

Lankoski, L., Smith, N., \& Van Wasserhove, L. (2016). Stakeholder judgments of value. Business Ethics Quarterly, 26(2), 227-256.

Lewin, A. Y., \& Volberda, H. W. (1999). Prolegomena on coevolution: A framework for research on strategy and new organizational forms. Organizational Science, 10(5), 519-534.

Lucea, R., \& Doh, J. (2012). International Strategy for the Non-market Context: Stakeholders, issues, networks, and geography. Business \& Politics, 14(3), 1-30.

Mahon, J. F. (1989). Corporate political strategy. Business in a Contemporary World., 2, 50-62.

Mahon, J. F., (2017). Issues management, forthcoming in P. Harris and C. S. Fleisher eds., Handbook of Public Affairs, $2^{\text {nd }}$. Ed., Thousand Oaks: Sage.

Mahon, J. F., \& McGowan, R. A. (1996). Industry as a player in the political and social arena: Defining the competitive environment. Greenwich, CT: Quorum Books.

Mahon, J. F., \& Wartick, S. L. (2012). Corporate social performance profiling: Using multiple stakeholder perceptions to assess a corporate reputation. Interna-tional Journal of Public Affairs, 12(1), 12-28.

Mason, R. O., \& Mitroff, I. (1980). Structuring ill-structured policy issues: Further explorations in a methodology for messy problems. Strategic Management Journal, 1, 331-342.

McMillan, C., \& Overall, J. (2016). Wicked problems: Turning strategic management upside down. Journal of Business Strategy, 37(1), 34-43.

Mitchell, R. K., Agle, B. R., \& Wood, D. J. (1997). Toward a theory of stakeholder identification and salience: Defining the principle of who and what really counts. Academy of Management Review, 22(4), 853-886.

Mitnick, B. M. (2001). The uses of political markets, paper presented at the National Meetings of the Academy of Management, Washington, DC, August.

Preston, L. E., \& Post, J. E. (1975). Private management and public policy: The principle of public policy. Englewood Cliffs, NJ: Prentice-Hall.

Rochefort, D. A., \& Cobb, R. W. (Eds.) (1994). The politics of problem definition: Shaping the policy agenda. Lawrence, KS: University Press of Kansas. 
Rumelt, R. P., Schendel, D. E., \& Teece, D. J. (1991). Strategic management and economics. Strategic Management Journal, 12(Winter special issue), 5-29.

Schattschneider, E. E. (1960). The semi-sovereign people: A realist's guide to democracy in America. New York: Holt.

Stout, L. (2012). The shareholder value myth: How putting shareholders first harms investors, corporations and the public. San Francisco, CA: Berrett-Koehler.

Waddock, S. A., \& Mahon, J. F. (1991). Corporate social performance revisited: Dimensions of efficacy, effectiveness, and efficiency. In J. E. Post (Ed.), Research in corporate social performance and policy, 12. (pp. 231-262). Greenwich, CT: JAI Press.

Waligo, V. M., Clarke, J., \& Hawkins, R. (2014). The 'leadership-stakeholder involvement capacity' nexus in stakeholder management. Journal of Business Research, 67(7), 1342-1352.

Wartick, S. L., \& Mahon, J. F. (1994). Toward a substantive definition of the cor-porate issue construct: A review and synthesis of the literature, Business and Society, 33 (3), December: 293-311.

Weiss, J. W. (2014). Business ethics: A stakeholder and issues management approach. San Francisco, CA: Berrett-Koehler Publishers.

How to cite this article: Mahon, J. F., Heugens, P. P. M. A. R., and McGowan, R. A. (2016), Blending issues and stakeholders: In pursuit of the elusive synergy, J Public Affairs, doi: 10.1002/ pa. 1635

\section{AUTHOR BIOGRAPHIES}

John F. Mahon is the John M. Murphy Chair of International Business

Policy and Strategy/professor of Management at the Maine Business
School, University of Maine. He received his DBA from Boston University, his MBA (with honors) from Bryant College, and his BS in Economics from the Wharton School at the University of Pennsylvania. He is the author or co-author of nearly 300 cases, papers, and book chapters.

Pursey Heugens is a professor of organisation theory, development, and change at the Department of Strategic Management and Entrepreneurship, Rotterdam School of Management, Erasmus University (RSM). His research interests include comparative corporate governance, business ethics, and bureaucracy, institutional, and demographic theories of organisation. Professor Heugens has won numerous awards for his research and teaching. He currently serves on the editorial boards of six scholarly journals. His research has been published in academic journals including the Academy of Management Journal, the Academy of Management Review, Organization Studies, and the Journal of Management Studies.

Richard McGowan, S. J., is an associate professor of the practice in the Finance Department at the Carroll School of Management at Boston College. The focus of his research is on the interaction of the business and public policy processes. Professor McGowan has published six books that focus on variety of topics that included gambling, tobacco, alcohol, and marijuana. Three of these books focused on the gambling industry with the latest entitled "The Gambling Debate." He is currently writing a book on the "Ethics of Disgust, Public Policy and the Sin Industries." He also has studied how microfinance influences the economic development of El Salvador. 